\section{Understanding the effects of humidity on ionic liquid-based electrochemical gas sensors}

\begin{tabular}{|c|c|}
\hline $\begin{array}{l}\text { Electrochemical gas sensors } \\
\text { are critically important tools } \\
\text { used in a wide variety of } \\
\text { everyday tasks, but with current } \\
\text { designs, their performance } \\
\text { can be significantly diminished } \\
\text { in hot, dry conditions. Debbie } \\
\text { Silvester at Curtin University, } \\
\text { Australia suggests that this } \\
\text { problem could be overcome } \\
\text { through the use of specialised } \\
\text { salts, which remain liquid at } \\
\text { room temperature. While these } \\
\text { substances are known to absorb } \\
\text { water, presenting their own } \\
\text { unique set of challenges relating } \\
\text { to humidity, her team's work } \\
\text { shows that they can be a } \\
\text { viable improvement } \\
\text { to existing } \\
\text { commercial gas } \\
\text { sensor designs } \\
\text { if the right } \\
\text { precautions } \\
\text { are taken. }\end{array}$ & $\begin{array}{l}\text { nenvironments where harmful gases } \\
\text { can reach dangerous levels, it is often } \\
\text { incredibly important to monitor levels } \\
\text { of the gases over time. In workplaces } \\
\text { including mines, airports and building } \\
\text { sites, as well as in healthcare, many lives } \\
\text { can depend on instruments which alert } \\
\text { us to the presence of deadly gases. At } \\
\text { the same time, quantifyying gas levels } \\
\text { is of crucial importance to researchers } \\
\text { monitoring the impact of human activities } \\
\text { on natural ecosystems. } \\
\text { Perhaps the most widely used } \\
\text { portable technique for monitoring gas } \\
\text { involves passing electrical charges } \\
\text { across solutions containing } \\
\text { electrolytes - which } \\
\text { separate into positively- } \\
\text { charged cations } \\
\text { and negatively- } \\
\text { charged anions } \\
\text { when dissolved } \\
\text { in solvents. }\end{array}$ \\
\hline
\end{tabular}

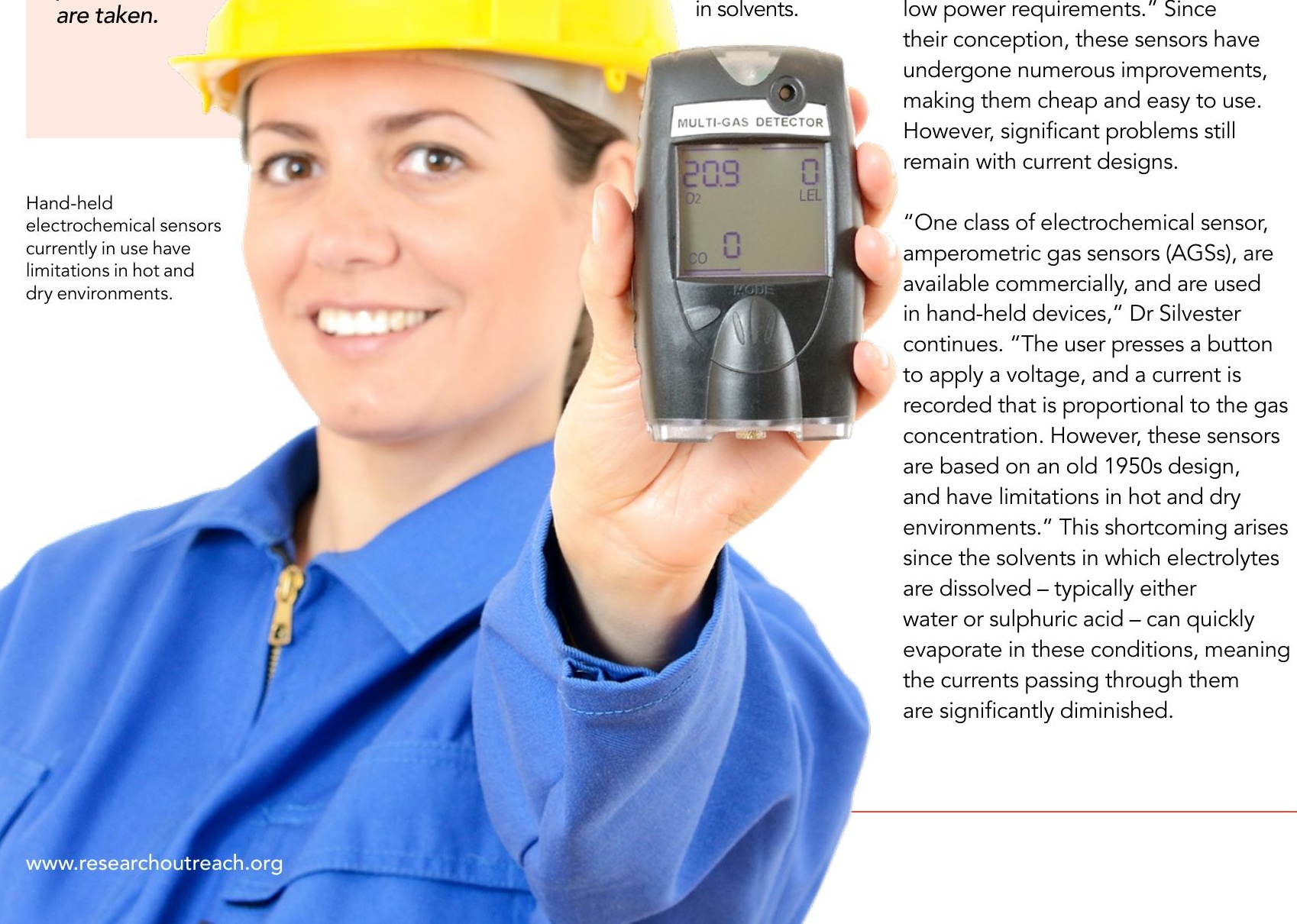

Known as electrochemical sensors, these devices have a gas-permeable to the sensing electrode. This electrode is connected with two other electrodes hrough a conductive solvent. The gas is either oxidised - losing electrons to the sensing electrode, producing a current, lectrode. The presence of certain gas will subsequently vary the a certain gas electrode, which the sensor translates into a read-out of the concentration in the surrounding environment. The membrane serves a dual function to filter out interfering gases and prevent evaporation of the solvent.

As Dr Silvester describes, "electrochemical sensors are often used due to their high sensitivity, high selectivity, low cost, portability, durability, wide detection range and low power requirements. "Since ( (om cheap and easy to use. amperometric gas sensors (AGSs), are vailable commercially, and are used cents." This shortcoming arises (T) we the currents passing through them membrane that allows diffusion of gas



REPLACING SOLVENTS WITH ROOM-TEMPERATURE SALTS In her research, Dr Silvester advocates an overhaul of electrochemical gas sensor designs, by replacing evaporationprone solutions with more robust room temperature ionic liquids (RTILs). Just like dissolved electrolytes, RTILs can carry electric currents through freely flowing anions and cations, acting as both the solvent and electrolyte. However, they also will not evaporate like waterof the gas permeble membre simplification of the sensor design. RTIL also have numerous other advantages, which Dr Silvester explains:

"RTILs are salts with low melting points, made of cations and anions that are physically and chemically stable, have wide electrochemical windows, intrinsic conductivity, wide liquid temperature range, high polarity and an ability to she says. "By using RTILs, we are able
sholv

to employ tiny volumes of less than a droplet, allowing the whole sensor device to be miniaturised to a size smaller than the materials and manufacturing costs."

Along with these advantages, salts as a whole - defined simply as assemblies of cations (positive ions) and an equal number of oppositely-charged anions "Thereass a diverse range of chemicals. "Thsible, simply by changing the che structure of the cation and anion," describes Dr Silvester. As it turns out, this selection is critically important to the
effectiveness of RTILs in electrochemical sensors, since the substances aren't without their own shortcomings.

\section{PROBING RESPONSES}

\section{TO HUMIDITY}

Despite the fact that RTILs typically perform well in hot, dry environments, their advantages appear to diminish in more humid conditions. "RTILs ar

RTILs are salts with low melting points, made of cations and anions that are physically and chemically stable. known to absorb water, and this can alter the electrode reactions occurring ectrode," Dr Silvester explains. "Since gas sensors are required (t) it is vital to understand the effects of humidity on the sensor response."

By testing how electrochemical sensors contaning RTLS with dilterent structures Dr Silvester's team aimed to humidity, which salts produced more stable currents as humidity varied, making them far more suitable In their latest study, the researchers observed the responses of different RTILs to oxygen, which is known to react in different ways depending on levels of humidity.

'Oxygen was chosen as a target gas, since the reaction mechanism is known to change from a one-electron reduction in dry conditions, to a multi-electron process in the presence of water. This change in electron number increases the current response, allowing us to investigate the water-repelling ability of different RTILs," continues Dr Silvester. "A number of optimum electrolyte." Because of this 
Force curves show distinct cation layers that are disrupted

effect, the team expected that RTILs with different chemical structures would dipo't in dferentways to humidry, but manifest themselves.

\section{HYDROPHOBIC LAYERS}

\section{OF CATIONS}

To probe the responses of each RTLL, Dr (T)ester and colleagues used a technique named 'cyclic voltammetry', which substance in response to a periodically changing voltage. In each case, the current across the salts varied significantly in the presence of humidity, with noticeable differences in the responses of RTILs with different structures. These differences in response arose since the salts can havions comprising different including their size, and the properties, which they repel water - known as their 'hydrophobicity'.

"The anion had the most effect on the current response at high humidity levels,
consistent with the bulk water solubility," describes Dr Silvester. "However, the current at lower humidity levels was mostly determined by the cation." The team determined that these differences in cation responses occur since cations assemble as a layer of positive charges at the electrode to balance the negative charge at the surface. Depending on the structure of the cation, they either form very dense hydrophobic layers that repe water well, or less dense layers with more hydrophilic cations
at repelling water.

The current response varies dramatically depending on the hydrophobic properties of the cation
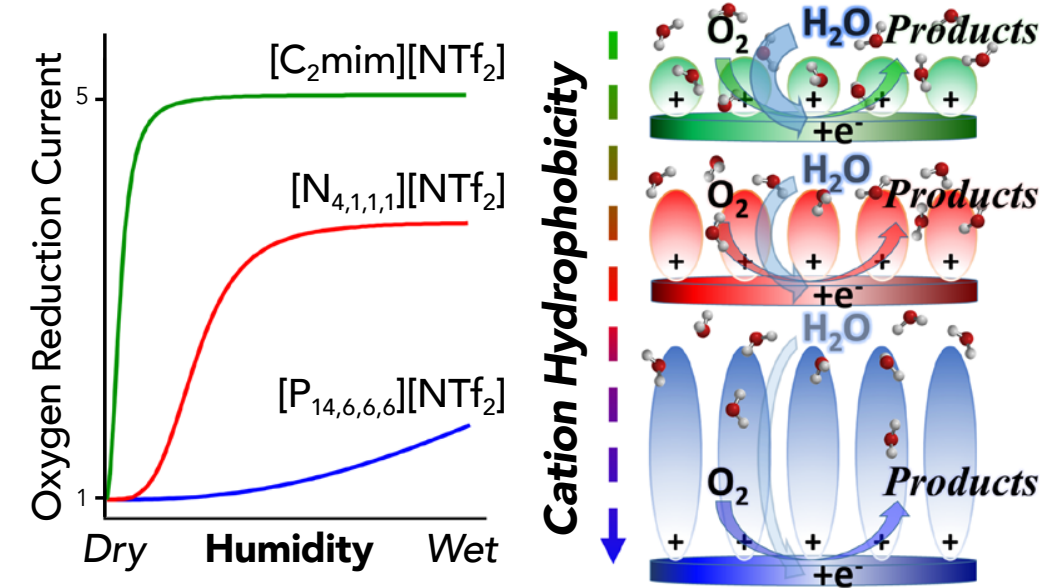
in the presence of water

\section{FINELY TUNED SHIELDS}

These cation layers have important Since RTILs are so varied, her team noted that the properties of the layers they form can be finely tuned by carefully of water, it becomes disrupted in the presence of water. Small, hydrophilic cations are unable to block the water (a) (This that in order to maintain a stable curren as humidity varies, RTILs with more as humidity varies, RTLs with more

Dry Humidity
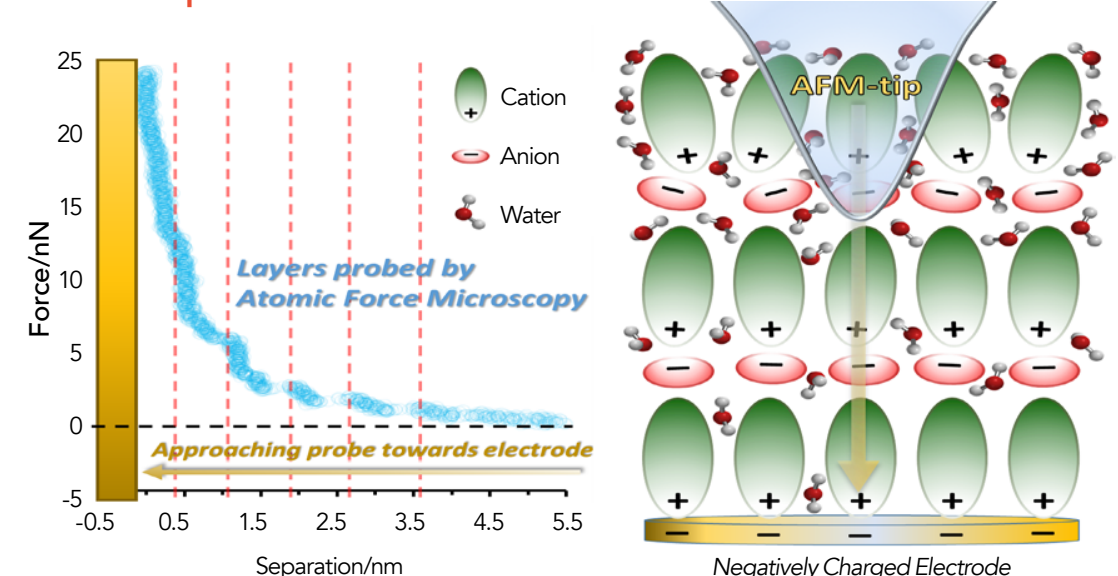

Small, hydrophilic cations are unable to block water... but larger hydrophobic cations can effectively shield the electrode. there is clear structuring in the absence cations that are less hydrophobic could be useful for applications other than gas sensing. "Alternatively, if a large change sensors, then the choice of hydrophilic

\section{IMPROVING ELECTROCHEMICAL}

GAS SENSORS

The team's discovery has important that by carefully selecting the RTIL to be used, electrochemical gas sensors effects of humidity. "Overall, this work shows the huge dependence on oxygen reduction current simply by changing the RTIL cation and anion," Dr Silvester summarises. "For applications where a stable current response is necessary, the use of highly hydrophobic and large RTIL cations and anions is recommended."

The insights gathered by Dr Silvester's team could soon allow for significant improvements to gas sensors; enabling them be miniaturised and made low cost, but also to maintain stable currents across a wide variety of environmental about improvements in a diverse range so applications, including workplace of
At the same time, they suggest that RTIL with humidity is desired, like for humidity implications; showing for the first time conditions. Such changes would bring

\section{Behind the Research}

\section{Dr Debbie Silvester}

E: d.silvester-dean@curtin.edu.au T: +61 (0)892667148 W: https://debbiesilvester.wordpress.com/

\section{Research Objectives}

The Silvester lab works at the interface of physical, analytical and materials methods and materials characterisation techniques to investigate electrode processes, from understanding fundamental behaviour to application-focused research.

\section{Detail}

Debbie Silvester

Curtin Institute for Functional Molecules and Interfaces School of Molecular and Life Sciences

Curtin University
GPO Box U1987

Perth

Curtin University $\begin{array}{ll}\text { Western Australia } 6845 & \text { INSTITUTE FOR FUNCTIONAL } \\ \text { MOLECULES AND INTERACES }\end{array}$ Australia

Debbie Silvester obtained her DPhil (PhD) at Oxford University, UK, in Dec 2008. She arrived at Curtin University in Western Australia in 2009. She has had three successive fellowships (Curtin Research Fellowship, ARC Discovery Early Career Rescarch Award and ARC Future Fellowship and was promoted to Associate Professor in 2018.

Funding

Australian Research Council (ARC Future Fellowship FT170100315)

- Sillaborators

- Dr Junqiao Lee (PostDoc, Curtin University)

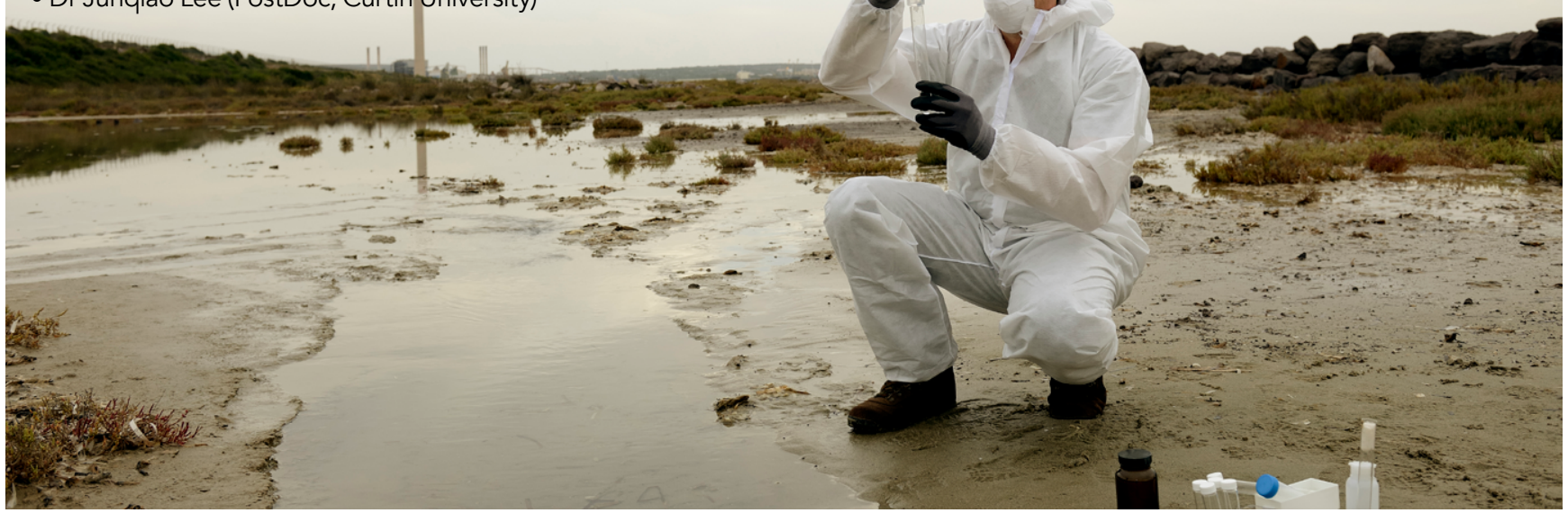

\section{References} Silvester, D.S. (2011). Recent advances in the use of ionic
liquids for electrochemical sensing. Analyst, 136(23), 4871 4882. https://doi.org/10.1039/C1AN15699C

Doblinger, S., Lee, J., Silvester, D. S. (2019). Effect of lonic Liquid Structure on the Oxygen Reduction Reaction Under

Silvester, D.S. (2019). New Innovations in lonic Liquid-based Miniaturised Amperometric Gas Sensors. Current Opinion

.tps://doi.org/10.1016/j.coelec.2019.03.001

\section{Personal Response}

\section{What is next for your research?}

IU This study has revealed that the choice of RTIL cation RTIL-based electrochemical gas sensors more robust and durable, the use of a liquid electrolyte may not be viable in a 'membrane-free' design. Therefore, we are now investigating gelled electrolytes - created by combining that do not flow. The presence of the polymers may also influence the structuring of ions near the electrode We plan to selectively design the chemistry of both the RTIL ions and polymer to absorb certain gases, to allow improved
selectivity over interfering gases and moisture. Humidified Conditions. The Journal of Physical Chemistry C. 